\title{
A Quality-Control Phantom for Digitization of Radiographs
}

\author{
Ethan J. Halpern, Peter D. Esser, Edward L. Nickoloff, and Philip O. Alderson
}

Quality control is fundamental to the clinical application of digital radiography. A $14 \times 17$-in phantom radiograph was designed to test digital image quality by measurement of five parameters: high-contrast spatial resolution, low-contrast discrimination, linearity of gray-scale response, high-frequency noise, and geometric distortion. The phantom was used to evaluate the AT\&T-Philips CommView picture archival and communications system (AT\&T Bell Laboratories, West Long Branch, NJ; Philips Medical Systems, Shelton, CT). High-contrast resolution was found to be greater along the diagonal axis of the system than along either the horizontal or vertical axis. Problems with low-contrast discrimination and linearity of gray-scale response were identified. This phantom provides a simple tool for daily quality assurance testing and an objective standard for comparison of image quality between different digital radiography systems.

(c) 1990 by W.B. Saunders Company.

KEY WORDS: Quality control, digital radiography, laser film scanner, teleradiology, picture archival and communication system (PACS).

I N RECENT YEARS, an increasing number of commercial teleradiology and picture archival and communication systems (PACS) have been placed into clinical use. Such systems provide mechanisms for the acquisition, transmission, and display of radiographs. Plain films are digitized on a variety of hardware platforms, including laser film scanners, video cameraframe grabber combinations, and charge-coupled device (CCD) cameras. Image quality varies considerably among these systems.

A large number of clinical trials have been performed to evaluate the quality of digital radiographic images. ${ }^{1-5}$ Several reports have focused on the physical characteristics of plain film images that have been digitized ${ }^{6}$ and on digital subtraction angiography. ${ }^{7}$ Many different test procedures were used in these studies. At the present time, however, there is no generally

From the Department of Radiology, Columbia Presbyterian Medical Center, New York, NY.

Address reprint requests to Ethan J. Halpern, MD, Department of Radiology, Columbia Presbyterian Medical Center, 622 West 168th St, New York, NY 10032.

(C) 1990 by W.B. Saunders Company. 0897-1889/90/0301-0010\$03.00/0 accepted quality assurance protocol for digital radiography.

A pattern developed by the Society of Motion Picture and Television Engineers (SMPTE) ${ }^{8}$ (Fig 1) has been widely used to evaluate video-based display systems. It provides bar phantoms to evaluate high-contrast resolution and varying levels of brightness to test gray-scale response. The bar phantoms of the SMPTE pattern are arranged to test both the horizontal and vertical limits of resolution for a standard television video system. Diagonal resolution is not tested. The pattern is not designed to evaluate the widely varying resolution capabilities of digital radiography systems. Furthermore, the SMPTE pattern does not adequately address the issue of lowcontrast discrimination. Therefore, we have designed a new phantom specifically for digital radiography.

Many factors affect ultimate image quality. ${ }^{9-12}$ We have designed a plain film phantom for digital radiography to focus on five primary parameters, including (1) high-contrast spatial resolution, (2) low-contrast discrimination, (3) linearity of gray-scale response, (4) high-frequency noise, and (5) geometric distortion. The goal was to design a simple standard phantom to facilitate the comparison, initial acceptance testing, and daily quality control for digital radiography systems.

\section{MATERIALS AND METHODS}

\section{The Phantom}

A $35 \times 43-\mathrm{cm}$ film phantom was composed on T-MAT L $\mathrm{x}$-ray film (Eastman Kodak, Rochester, NY) as shown in Fig 2. This phantom combines four basic test patterns: (1) high-contrast line-pair patterns to measure high-contrast spatial resolution in the horizontal, vertical, and diagonal directions; (2) Rose-hole patterns to evaluate low-contrast discrimination at both the lighter and darker extremes of film density ordinarily seen in clinical practice; (3) gray-scale step patterns to calibrate the system response to changes in optical density and to quantitate the high-frequency noise; and (4) grid patterns, to test for geometric distortion, placed at the margins of the image

Each of these test patterns was individually exposed. All exposures were performed with a $0.6-\mathrm{mm}$ focal spot, using a target to film distance of 56 in. Physical phantoms were placed directly on the film cassette. A grid was not used.

The high-contrast line-pair patterns were created by exposing a commercially available $0.1-\mathrm{mm}$ lead line pair phantom 


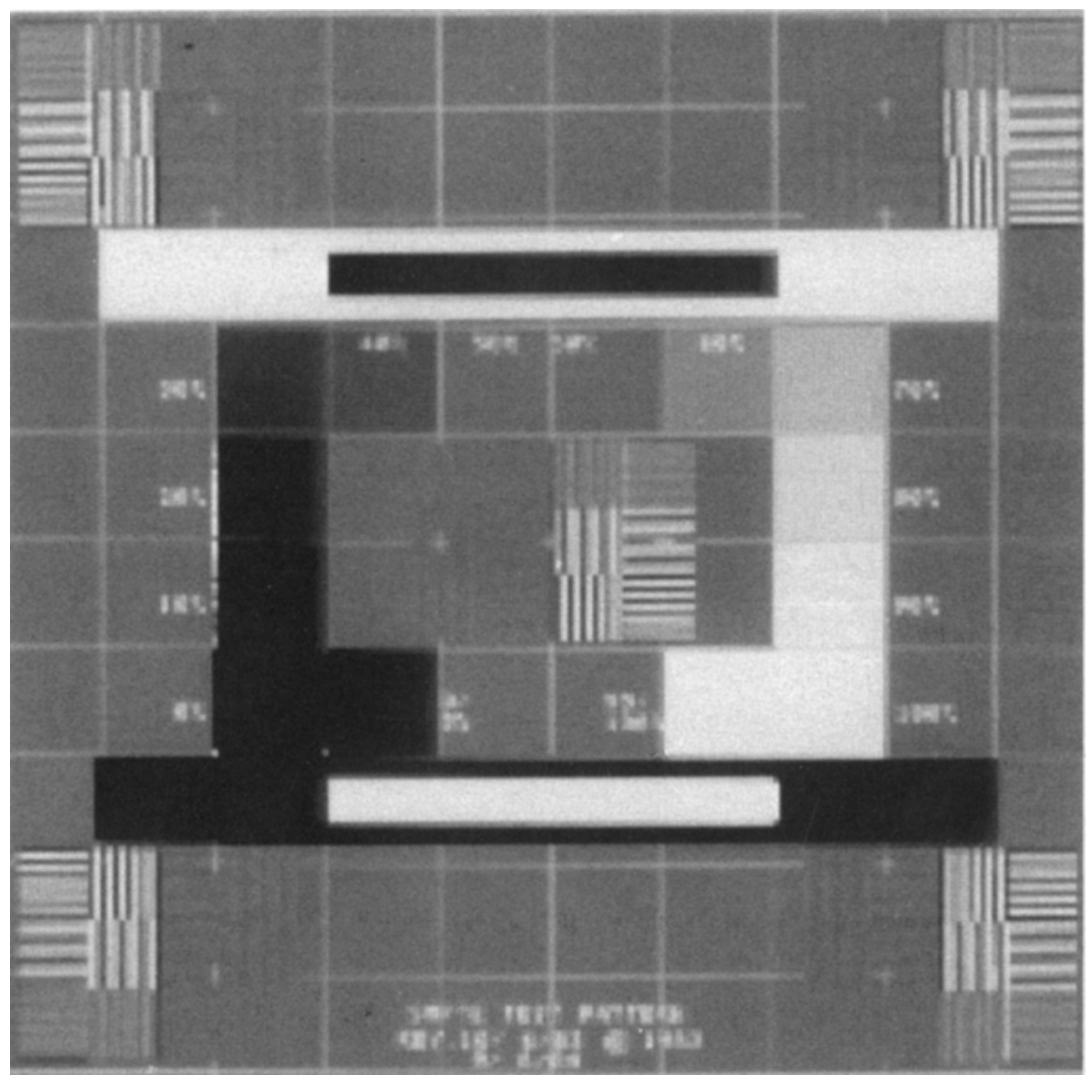

Fig 1. SMPTE pattern, displayed after digitization on the CommView 2.0 system. This pattern is frequently used to calibrate monitor brightness. A limited range of resolution and contrast values are tested.

(Nuclear Associates, Carlo Place, NY) at $50 \mathrm{kVp}$ and 0.8 mAs. The line-pair frequencies span the range of 0.6 to 5.0 line pairs per millimeter. Two diagonal patterns, a single horizontal pattern, and a single vertical pattern were exposed across the center of the film phantom.

Low-contrast Rose-hole patterns bracket both sides of the high-contrast bar patterns. Hole sizes in these patterns range from $0.6 \mathrm{~mm}$ to $9.4 \mathrm{~mm}$. Background optical density for the darker Rose-hole pattern ranges from 2.46 to 2.52 optical density units. The larger holes in that pattern have an optical density of 2.65 density units. Background optical density for the lighter Rose-hole pattern ranges from 0.24 to 0.25 optical density units. The larger holes in this pattern have an optical density of 0.27 density units. Thus, both the dark and light Rose patterns provide a maximum contrast of $8 \%$ for the largest holes. The Rose-hole patterns are oriented perpendicular to the cathode-anode axis to minimize heel effect.

The Rose phantom was constructed with four parallel slabs of lucite measuring $6,8,10$, and $13 \mathrm{~mm}$, respectively. Ten holes, varying in size from $0.6 \mathrm{~mm}$ to $9.4 \mathrm{~mm}$, were drilled into each of these slabs. The Rose phantom was exposed at 75 $\mathrm{kVp}$ and $0.1 \mathrm{mAs}$ to create the light low-contrast pattern, and at $125 \mathrm{kVp}$ and $0.2 \mathrm{mAs}$ to create the dark low-contrast pattern. A model 301 densitometer (X-Rite; Grandville, MI) was used to measure optical densities on these patterns.

Optical density step patterns are present on either side of the film phantom. Each pattern has 21 steps of increasing optical density ranging from 0.18 to 3.45 optical density units. These patterns were exposed with a 21 -step sensitome- ter (X-Rite). Optical density values at each step were calibrated with a model 301 densitometer.

The grid lines at each end of the phantom are linear, and spaced at $3.3 \mathrm{~mm}$ in both the horizontal and vertical directions. They were created by exposing a copper wire mesh at $50 \mathrm{kVp}$ and $1.0 \mathrm{mAs}$.

\section{The PACS System}

The film phantom described was initially digitized on a CommView digital radiography system, software release 1.0 (AT\&T Bell Laboratories, West Long Branch, NJ and Philips Medical Systems, Shelton, CT). This system uses a model FD2000 laser film scanner (Dupont, Wilmington, $\mathrm{DE}$ ), operating at $1,024 \times 842$-pixel resolution. Images were acquired with 8 bits of image data per pixel and were displayed on a results-viewing station (RVS) monitor. The phantom was also digitized on a CommView digital radiography system, software release 2.1. This updated version acquires digital images at $2,048 \times 1,684$-pixel resolution, with 12 bits of image data per pixel. These images were displayed on an enhanced graphics station (EGS) monitor. A zoom feature was used to view these images at full resolution.

\section{Quality-Control Procedure}

Image quality was qualitatively evaluated by visual inspection of the digitized phantom at the display monitor (RVS or EGS). The visual inspection was performed by the primary author and two other independent observers. High-contrast 

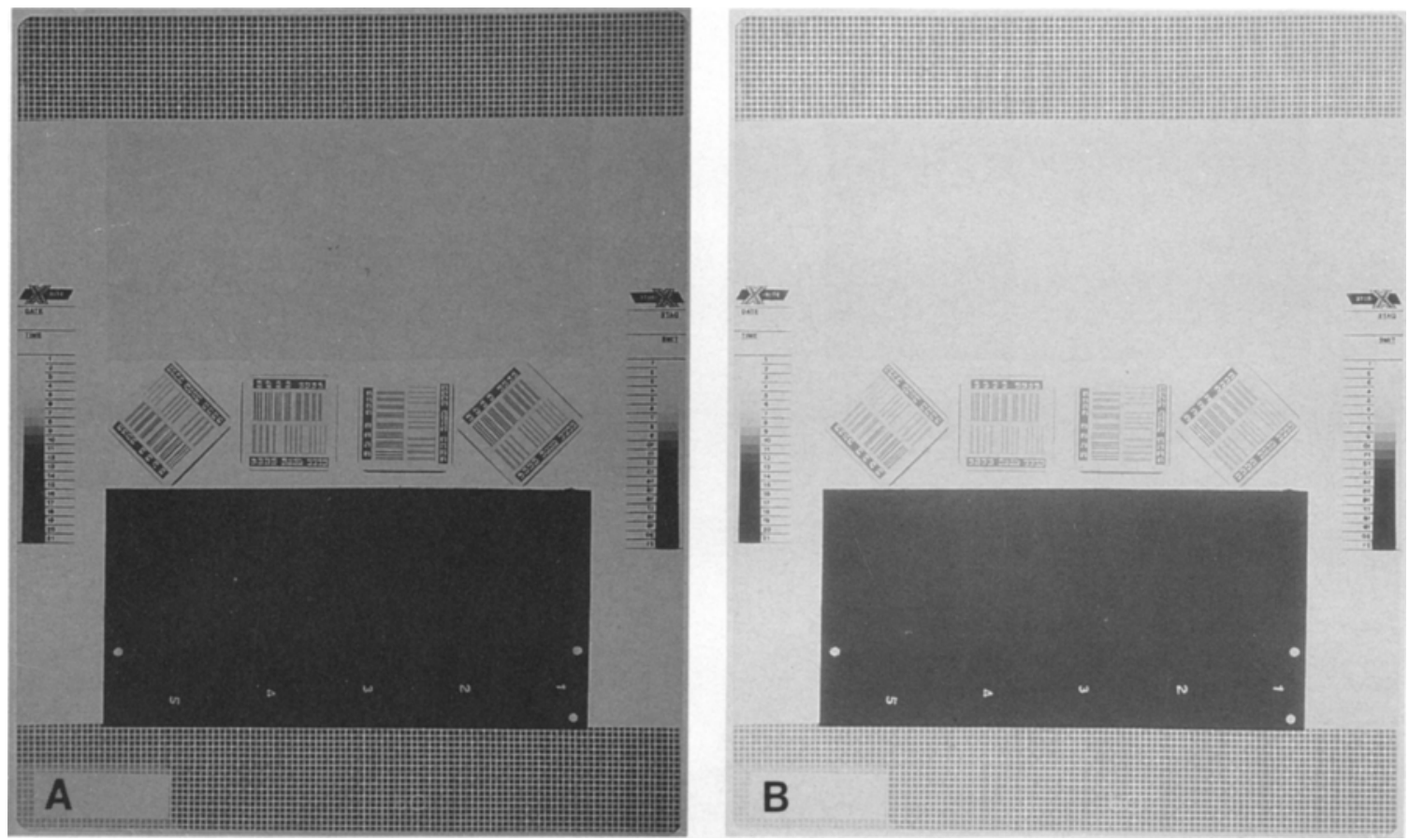

Fig 2. Quality-control phantom for digital radiology. (A) Standard exposure. (B) Light exposure to show the low-contrast Rose holes present with the dark background.

resolution was identified as the highest line-pair frequency in which individual lines were clearly distinguished..$^{13-14}$ The minimal perceptible hole diameters for the Rose patterns was interpreted as a measurement of low-contrast discrimination. ${ }^{13.15-16}$ Gray-scale step tablets were inspected to determine the number of visibly distinct steps. The circles within the Rose patterns and the squares and straight lines on the grids were inspected for geometric distortion. Magnification and window-level functions were used when necessary to appreciate fine details. Contrast and brightness controls were adjusted to optimize appreciation of details on the digitized patterns.

Additional quantitative quality-control procedures were performed to provide an objective quality-control evaluation. For high-contrast resolution, digital contrast was plotted as a function of the line-pair frequency (analogous to contrast response curves $^{13}$ ). For each high-contrast line-pair group, contrast was calculated as

$$
\left[\left(D_{\text {space }}-D_{\text {bar }}\right) / D_{\text {background }}\right] \times 100 \%
$$

where $D_{b a r}$ represents the mean digital pixel value along the bar, $D_{\text {space }}$ represents the mean digital pixel value along the space between the bars, and $D_{\text {background }}$ represents the background digital pixel value. For the lower frequency patterns, $\mathrm{D}_{\text {background }}=\mathrm{D}_{\text {space}}$.

For low-contrast discrimination, the contrast between the smallest perceptible holes and their background in the Rose pattern was plotted as a function of minimal perceptible hole diameter. ${ }^{15}$ Mean digital pixel values were calculated within each step of the gray-scale step tablet and plotted as a function of optical density on the film phantom. ${ }^{17}$ Standard deviations associated with these mean values were tabulated to quantitate high-frequency noise. ${ }^{18}$ Finally, the number of pixels between successive grid lines was measured in both the horizontal and vertical directions to detect geometric distortion.

\section{RESULTS}

For the CommView version 1.0 system, highcontrast spatial resolution was measured at 1.4 line pairs per millimeter in both diagonal axes, and approximately 1.2 line pairs per millimeter in the vertical and horizontal axes (Fig 3A and B). Plots of digital image contrast versus linepair frequency confirmed these resolution limitations (Fig 3C). The CommView version 2.1 system provided high-contrast spatial resolution of 2.5 line pairs per millimeter in both diagonal axes, 1.6 line pairs per millimeter in the vertical axis, and 1.8 line pairs per millimeter in the horizontal axis. Variations of up to 0.2 line pairs per millimeter were noted in the visual assessment of high-contrast spatial resolution by the two independent observers.

Low-contrast discrimination as evaluated by minimal perceptible hole diameter on the Rose patterns was worse with dark backgrounds than with light backgrounds for the CommView version 1.0 system. With the updated 2.1 system, 
Fig 3. High-contrast resolution patterns. (A) A diagonally oriented line-pair pattern has been digitized with the CommView version 1.0 system. (B) Identical pattern with horizontally oriented line pairs to test vertical resolution. (C) Contrast transfer function. A plot of digital image contrast at varying line-pair frequencies. As digital contrast approaches zero,

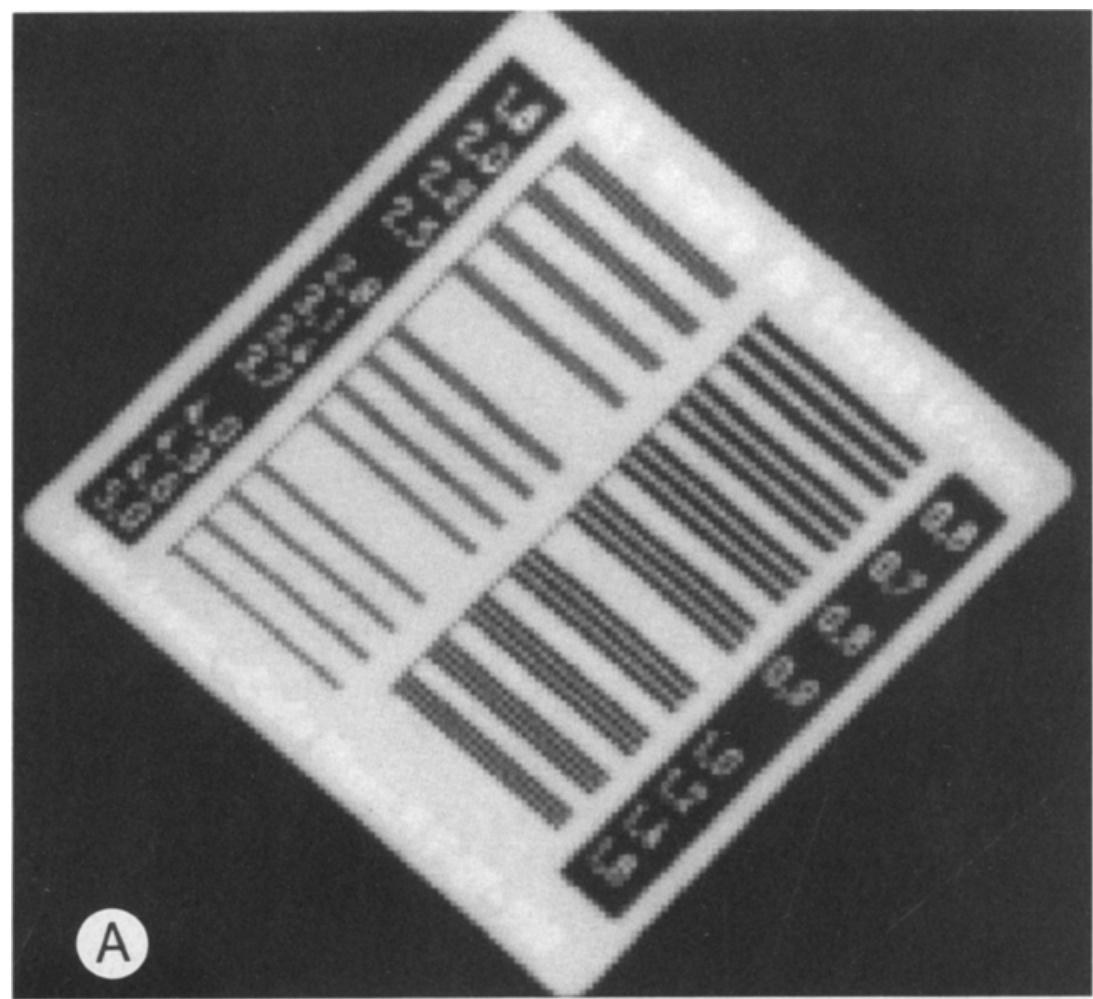
line pairs are no longer visible.

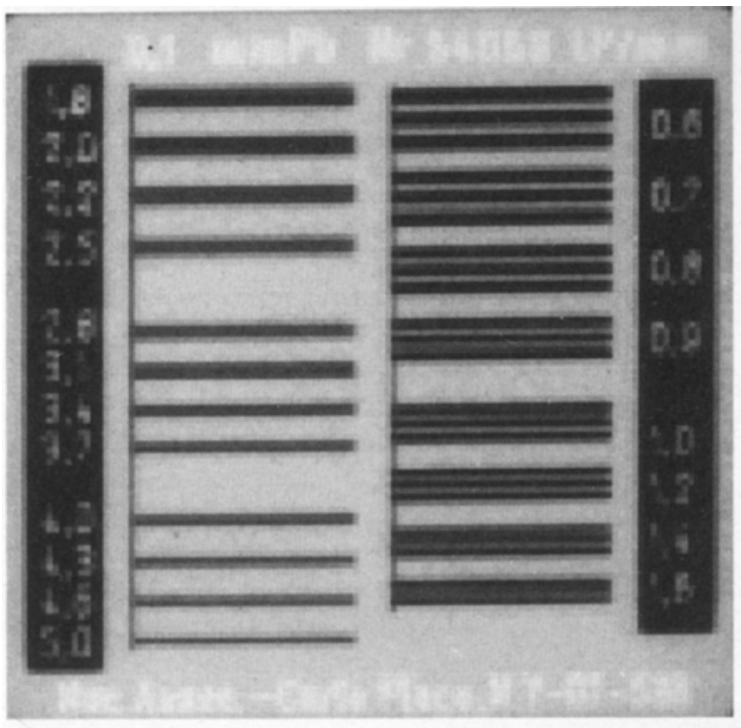

B

low-contrast discrimination was present for hole sizes as small as $1 \mathrm{~mm}$ and was equal for both the darker and lighter patterns. Plots of Rose-hole contrast versus minimal perceptible diameter (not shown) corroborated these findings.

Initial studies with the CommView 1.0 system yielded a poor response to changing optical

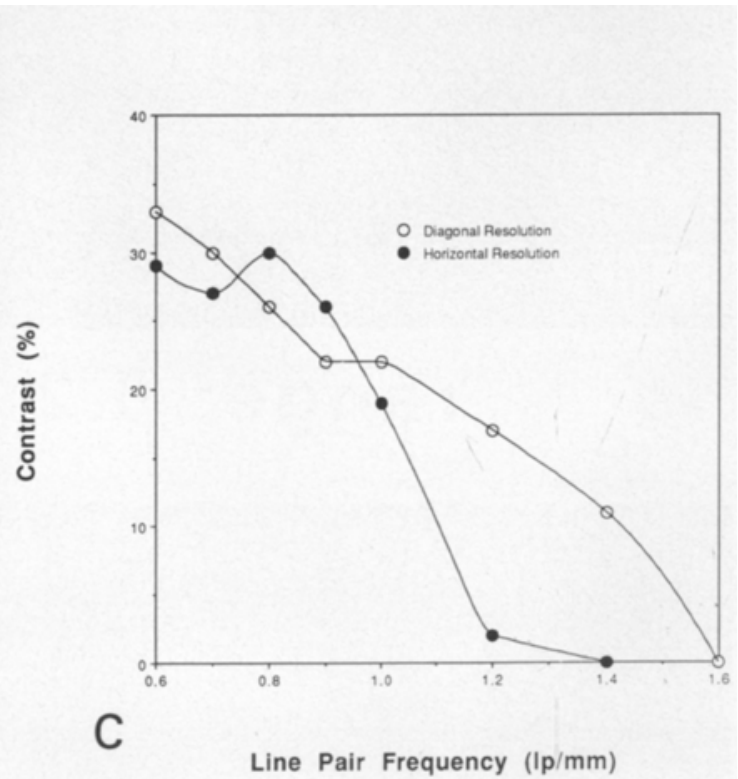

density values above 1.6 optical density units (Fig 4A). After modification of the look-up table (used to map 12-bit output from the digitizer into 8-bit data), these darker shades were more easily distinguished (Fig 4B). Quantitative analysis revealed that the initial digital pixel values varied logarithmically with optical density (Fig 4C). 
Following modification of the look-up table, a nearly linear response was observed over a range of 0.2 to 3.4 optical density units (Fig 4C).

Pixel values for the CommView 2.1 system varied linearly with optical density (Fig 4D). Using the window-level feature, distinct gray shades were visible on the EGS monitor for film densities in the range of 0.2 to 3.0 optical density units. However, for optical density values above 2.5 , there was a notable difference in the digital pixel values obtained from the two sides of the phantom. A nonlinear decrease was detected in the pixel values obtained from the strip on the left side of the phantom.

Only a minimal quantity of high-frequency noise was detectable in the CommView 1.0 system. This noise was found only for optical densities above 2.5 optical density units (Fig
4D). No high-frequency noise was identified in lighter areas. However, the 12-bit/pixel CommView 2.1 system revealed a significant level of high-frequency noise. In lighter regions $(\sim 0.2$ to 0.4 optical density units) the standard deviation of pixel values measured 4 to 5 digital units. In the darker areas ( 3.0 to 3.4 optical density units) the standard deviation of pixel values measured 60 to 100 digital units. Thus, in 12 bits of image data, there was approximately 2 bits of noise in the lighter parts of the image and 6 bits of noise in the darker parts of the image. These noisy bits were presumably truncated in the 8-bit/pixel images of the 1.0-version software.

To be certain that the increased noise in the darker portions of the image were not secondary to noise on the film phantom, computed tomographic images produced with a laser scanner

\section{range: 0.2 to 2.2 O.D.U.}

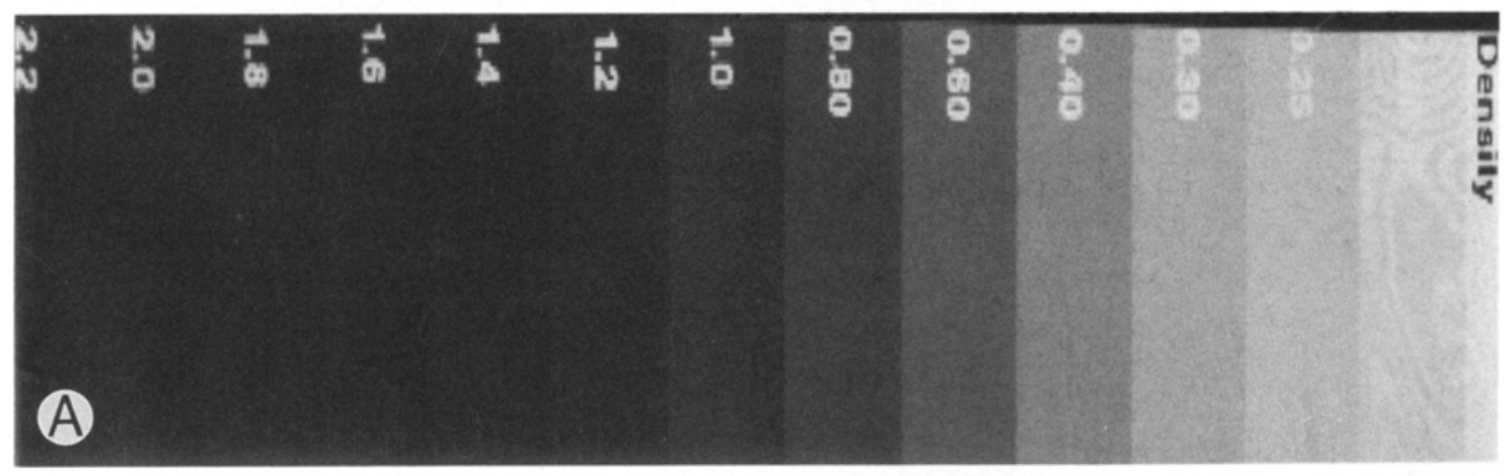

\section{range: 0.2 to 3.4 O.D.U.}

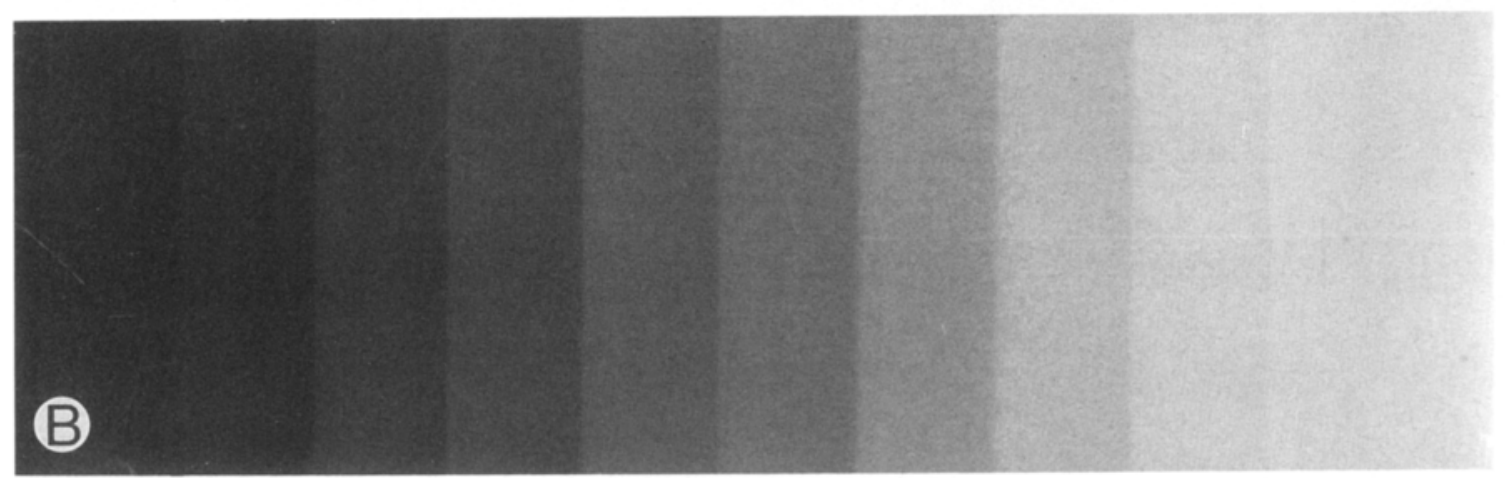

Fig 4. Linearity of gray-scale response. Error bars represent standard deviations. Sample size = 200 pixels at each optical density step. (A) Initial gray-scale phantom digitized on CommView version 1.0 system. Areas with optical densities greater than 1.6 optical density units cannot be distinguished. (B) Gray-scale phantom with a range of 0.2 to 3.4 optical density units was digitized after modification of a look-up table in the version 1.0 system. There is improved contrast in darker areas. 
were digitized. The black background around each computed tomographic image on these films revealed little graininess to visual inspection with a magnifying lens. However, the digitized images of these films appeared distinctly grainy when magnified. The digital pixel values in these black regions yielded standard deviations about the same as those found for the darkest portions of the film phantom.

There was no detectable geometric distortion in the digitized images for either of the two systems.

\section{DISCUSSION}

Degradation of image quality is often difficult to appreciate with digitized clinical images. ${ }^{19-20}$ Any particular set of clinical images might not
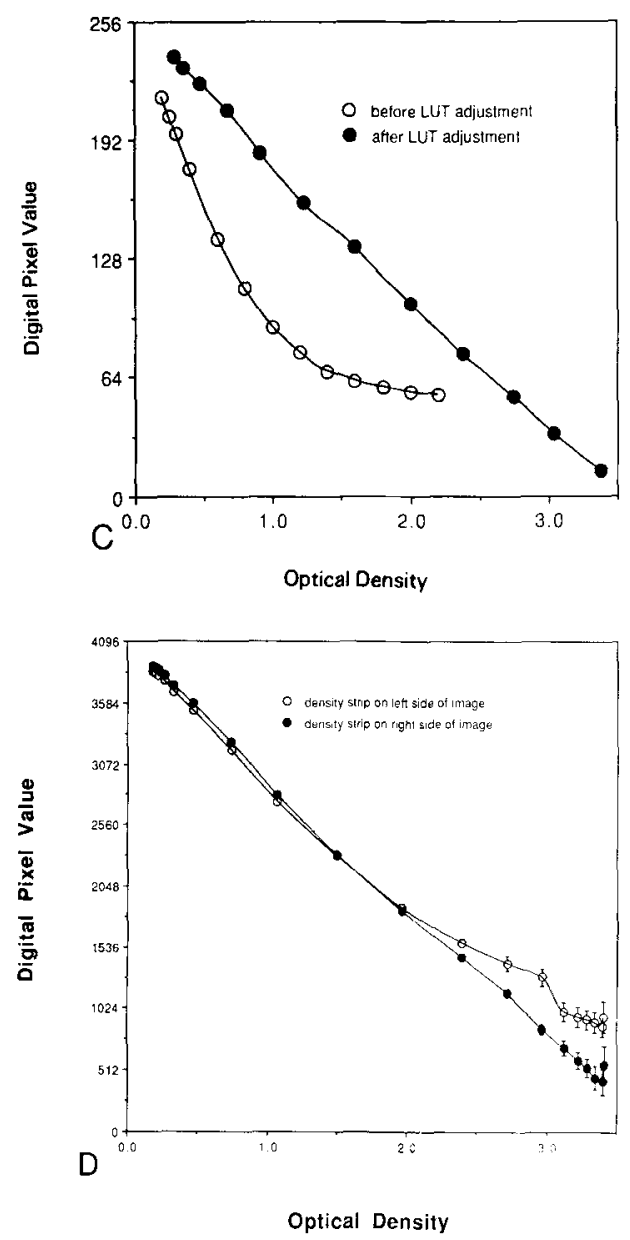

Fig 4. (Cont'd). (C) Plot of digital pixel values versus optical density for the phantoms shown in (A) and (B). (D) Plot of digital pixel values versus optical density for the CommView version 2.1 system. Note that the scale has changed from 0-255 (8-bit data) to 0-4095 (12-bit data). adequately test the physical limitations of a digital system. Phantoms, however, may be designed to evaluate specific parameters affecting image quality. Thus, phantoms may permit the early detection of quality-control problems not easily detected in clinical images. At the study institution, initial clinical test images with the CommView 1.0 system were inspected by three radiologists, who found the images to be of suboptimal quality. The specific difficulty with low-contrast discrimination in darker regions, however, was not initially appreciated with clinical test images. Analysis of gray-scale response with our phantom (Fig 4) suggested a clear deficiency in contrast discrimination for optical densities above 1.6. Once the problem was rectified, these same radiologists found that the clinical image quality was improved.

At present, there is no accepted standard phantom for quality control of digital radiography. The authors have designed a film phantom to test several basic parameters of digital image quality. Our phantom may provide both a qualitative and quantitative analysis of image quality. Qualitative analysis of the digitized image of the phantom provides a simple, reproducible qualitycontrol protocol that should be suitable for the needs of many departments. Unfortunately, visual analysis is somewhat subjective. This is further complicated by aliasing, which is introduced into the test patterns as the pattern size approaches the limiting resolution of the system. Quantitative evaluation of a digitized image of the phantom may be used to provide a more objective measure of image quality. However, quantitative analysis requires access to the digital pixel data as well as a certain level of expertise with computers to manipulate those data.

In the authors' experience, evaluation of both high-contrast resolution and low-contrast discrimination may be performed in an accurate, reproducible manner by simple visual inspection. Additional quantitative information is obtained by plotting the contrast transfer function (Fig 3C) or by calculating the digital contrast present in the minimal perceptible Rose holes. Visual detection of geometric distortion is also fairly accurate. However, determinations of the linearity of gray-scale response and high-frequency noise are best accomplished by quantitative analysis of the 
digital data (Fig 4). It is appropriate for vendors to provide access to these data for quality-control purposes.

A quality-control phantom for digital radiography has been described that is easily constructed using components generally available in a radiology department. Given the varying quality (and cost) of digital radiography systems, a single standard for performance cannot be defined. Individual standards, however, may be determined by clinical trials for particular tasks. The phantom in the present study provides objective criteria for comparison of image quality among different digital radiology systems. Its test patterns are appropriate for a wide spectrum of spatial resolution and contrast discrimination. Therefore, it may be applied equally well to high-quality systems that use a laser scanner to digitize films and to less expensive systems that rely on the digitization of a video signal. Regular quality-control testing for digital radiography systems with a phantom such as this one can be effectively used to ensure high-quality clinical images.

\section{REFERENCES}

1. Gayler BW, Gitlin JN, Rappaport W, et al: Teleradiology: An evaluation of a microcomputer-based system. Radiology 140:355-360, 1981

2. Curtis DJ, Gayler BW, Gitlin JN, et al: Teleradiology: Results of a field trial. Radiology 149:415-418, 1983

3. Goodman LR, Roley WD, Wilson CR, et al: Digital and conventional chest images: Observer performance with film digital radiography system. Radiology 158:27-33, 1986

4. Kagetsu NJ, Zulauf DRP, Ablow RC: Clinical trial of digital teleradiology in the practice of emergency room radiology. Radiology 165:551-554, 1987

5. Kundel HL, Mezrich JL, Brickman I, et al: Digital chest imaging: Comparison of two film image digitizers with a classification task. Radiology 165:747-752, 1987

6. Vranckx J, Strul B: Performance evaluation of a laser digitizer. SPIE Proceedings 767:524-528, 1987

7. High M, Cohen G, Lin PJ, et al: Performance evaluation and quality assurance in digital subtraction angiography, in American Association of Physicists (ed): Medicine Report No. 15. New York, NY, American Institute of Physics, 1985

8. Gray JE, Lisk KG, Haddick DH, Harshbarger JH, Oosterhof A, Schwenker R: Test pattern for video displays and hard-copy cameras. Radiology 154:519-527, 1985

9. Dainty J, Shaw R: Image Science. London, England, Academic, 1974

10. Haus AG (ed): The Physics of Medical Imaging: Recording System Measurements and Techniques. New York, NY, American Association of Physicists in Medicine, 1979
11. Brody WR: Digital Radiography. New York, NY, Raven, 1984

12. Barrett $\mathrm{HH}$, Swindell W: Radiographic Imaging: The Theory of Formation, Detection and Processing. New York, NY, Academic, 1981

13. Burgess AE, Humphrey K, Wagner RF: Detection of bars and discs in quantum noise. SPIE Proceedings of 173:34-40, 1979

14. Rossi RP, Hendee WR, Chuck R, et al: An evaluation of rare earth screen/film combinations. Radiology 121:465471,1976

15. Rose A. Vision: Human and Electronic. New York, NY, Plenumum, 1974

16. Cohen G, Wagner LK, Amtey SR, et al: Contrastdetail-dose and dose efficiency analysis of a scanning digital and a screen-film-grid radiographic system. Med Phys 8:358367,1981

17. Haus AG, Rossman K, Vyborny C, et al: Sensitometry in diagnostic radiology, radiation therapy and nuclear medicine. J Appl Photo Eng 3:144, 1977

18. Wagner RF: Toward a unified view of radiological imaging systems, part II: Noisy images. Med Phy 4:279-296, 1977

19. Kundel HL, Revesz G, Stauffer HM: Evaluation of television image processing. Invest Radiol 3:44-50, 1968

20. Revesz G, Kundel HL: Effects of non-linearities on television display of $x$-ray images. Invest Radiol 6:315-320, 1971 